\title{
Polyphenols with Antiulcerogenic Action from Aqueous Decoction of Mango Leaves (Mangifera indica L.)
}

\author{
Juliana Aparecida Severi ${ }^{1}$, Zeila Pinheiro Lima ${ }^{2}$, Hélio Kushima ${ }^{2}$, Alba Regina Monteiro \\ Souza Brito ${ }^{3}$, Lourdes Campaner dos Santos ${ }^{4}$, Wagner Vilegas ${ }^{4}$ and Clélia Akiko Hiruma- \\ $\operatorname{Lima}^{2, *}$
}

1 Pharmacos and Drugs Department, Pharmaceutical Sciences Faculty, São Paulo State UniversityUNESP, c.p.355, Zip Code: 14801-902, UNESP, Araraquara, SP, Brazil; E-mail: juseveri@yahoo.com.br (J-A.S.)

2 Physiology Department, Biosciences Institute, São Paulo State University-UNESP, c.p. 510, Zip Code: 18618-000, Botucatu, SP, Brazil; E-mail: zeilabio@hotmail.com (Z-P.L.), heliokushima@gmail.com (H.K.)

3 Physiology and Biophysics Department, Biology Institute, Campinas State University-UNICAMP, c.p. 6109, Zip Code: 13083-970, Campinas, SP, Brazil; E-mail: abrito@unicamp.br (A-R.M.)

4 Organic Chemistry Department, Chemistry Institute, São Paulo State University-UNESP, c.p. 355, Zip Code: 14800-900, UNESP, Araraquara, SP, Brazil; E-mail: vilegasw@gmail.com (W.V.), loursant@iq.unesp.br (L-C.S.)

* Author to whom correspondence should be addressed; E-mail: hiruma@ibb.unesp.br.

Received: 1 December 2008; in revised form; 12 January 2009 / Accepted: 22 January 2009 / Published: 10 March 2009

\begin{abstract}
This study was designed to determine the gastroprotective effect of a Mangifera indica leaf decoction (AD), on different experimental models in rodents. The administration of $\mathrm{AD}$ up to a dose of $5 \mathrm{~g} / \mathrm{kg}$ (p.o.) did not produce any signs or symptoms of toxicity in the treated animals, while significantly decreasing the severity of gastric damage induced by several gastroprotective models. Oral pre-treatment with AD $(250,500$ or $1000 \mathrm{mg} / \mathrm{kg}$ ) in mice and rats with gastric lesions induced by $\mathrm{HCl} / \mathrm{ethanol}$, absolute ethanol, non-steroidal anti-inflammatory drug (NSAID) or stress-induced gastric lesions resulted in a significant decrease of said lesions. Phytochemical analyses of AD composition demonstrated the presence of bioactive phenolic compounds that represent $57.3 \%$ of total phenolic content in this extract. Two main phenolic compounds were isolated, specifically
\end{abstract}


mangiferin (C-glucopyranoside of 1,3,6,7-tetrahydroxyxanthone) and C-glucosylbenzophenone (3-C- $\beta$-D-glucopyranosyl-4',2,4,6-tetrahydroxybenzophenone). These findings indicate the potential gastroprotective properties of aqueous decoction from $M$. indica leaves.

Keywords: Mangifera indica; Antiulcer gastric; Mangiferin; Benzophenone; Phenolic compounds.

\section{Introduction}

Acid related disorders are common conditions in the general population. Furthermore, clinical experience has shown that acid-related symptoms as well as duodenal ulcers return quickly after cessation of drug treatments, raising the possibility of rebound hypersecretion [1]. Therapy in the future will continue to focus on control of acid secretion and subsequent reversal of mucosal damage and inflammation [2].

Mangifera indica L. (Anacardiaceae) is one of the most important tropical plants marketed in the world [3]. It is a large tree that grows in tropical and subtropical regions, whose fruits are widely appreciated by the population. There are many traditional medicinal uses for the bark, roots and leaves of M. indica throughout the globe [3]. This plant was listed in TRAMIL (Program of Applied Research to Popular Medicine in the Caribbean) as an agent for the treatment of diarrhea, fever, gastritis and ulcers $[4,5]$. Phytochemical research from different parts of $M$. indica has demonstrated the presence of phenolic constituents, triterpenes, flavonoids, phytosterols, and polyphenols [6-10]. This species is purported to posses numerous therapeutic uses including analgesic, anti-inflammatory [11], immunostimulant [12-14], antioxidant [15-17], spasmolytic, antidiarrhea [18], dyslipidemic [19], antidiabetic [20,21], antiamebic [22], anthelminthic, antiallergic [23] and antibacterial applications [24]. Moreover, a previous work carried out by our group showed antiulcerogenic and healing effects of aqueous decoction of $M$. indica flowers [25]. However, the great demand for this decoction has diminished the availability of $M$. indica fruits that are widely appreciated by the population as food. Therefore, the study aimed to evaluate the antiulcer activity of the aqueous decoction (AD) obtained from the leaves of Mangifera indica using different in vivo experimental models in rodents followed by its phytochemical investigation.

\section{Results and Discussion}

The gastroprotective action exerted by an aqueous decoction (AD) of Mangifera indica leaves emerged from an ethnobotanical inventory from the Traditional Medicine of the Islands (TRAMIL project) for development of the Caribbean Medicinal Plant Pharmacopoeia. As part of this pharmacological study, the $\mathrm{AD}$ obtained from leaves of $M$. indica was first investigated in relation to its acute toxicity in vivo. This application suggests that there would be no toxic effects from the administration of this decoction. A single oral administration of AD from $M$. indica via the oral route at dose of $5 \mathrm{mg} / \mathrm{Kg}$ did not produce any signs or symptoms of toxicity in the treated animals. During the following 14 days after the administration of $\mathrm{AD}$, no animals died and there were no significant 
alteration in water or food consumption. At autopsy, no significant change or lesion was observed in the viscera of any animal (Table 1). Loomis and Hayes [26] described the classification of some chemical agents into categories of toxicity in which the dose of $5 \mathrm{~g} / \mathrm{Kg}$ was categorized as practically nontoxic, a result which indicates that this preparation from $M$. indica has no acute toxicological effect when administered orally. These results demonstrated the need for continuation of pharmacological studies on the oral administration of this decoction and motivated us to continue with the assays.

Table 1. Evaluation of the acute toxicity of aqueous decoction (AD) of $M$. indica leaves (5 $\mathrm{g} / \mathrm{Kg}$, p.o.) in male Swiss mice $(\mathrm{n}=10)$.

\begin{tabular}{lll}
\hline Weight (g) & Control & \multicolumn{1}{c}{ AD } \\
\hline Corporal & $43.00 \pm 0.63$ & $43.00 \pm 1.18$ \\
Kidney & $0.59 \pm 0.31$ & $0.52 \pm 0.02$ \\
Liver & $2.00 \pm 0.72$ & $1.82 \pm 0.09$ \\
Heart & $0,23 \pm 0.01$ & $0.18 \pm 0.02$ \\
Lungs & $0.26 \pm 0.02$ & $0.23 \pm 0.01$ \\
\hline Mortality & $0 / 10$ & $0 / 10$ \\
\hline
\end{tabular}

Results are mean \pm S.E.M; $n=10$. Student's t test.

Not significant $\mathrm{p}>0.05$.

Intragastric application of absolute ethanol has long been used as a reproducible method to induce gastric lesions in experimental animals [27]. Recent studies have demonstrated that ROS (reactive oxygen species) such as superoxide anion radical, hydroxyl radical $(\mathrm{OH})$ and lipid peroxidation play an important role in pathogenesis of acute gastric damage induced by ethanol [28]. ROS provoke severe changes at the cellular level leading to cell death because of their extreme reactivity [29]. The oral administration of AD before the induction of gastric lesion by absolute ethanol significantly decreased the gastric lesions relative to the control group in which $500 \mathrm{mg} / \mathrm{Kg}$ generated $55 \%$ of inhibition, while $1,000 \mathrm{mg} / \mathrm{Kg}$ produced $95 \%$ of inhibition (Figure 1). The gastric injury caused by ethanol plus hydrochloric acid also can be seen in Figure 1. The pretreatment with AD (at doses of 500 or $1,000 \mathrm{mg} / \mathrm{Kg})$ before $\mathrm{HCl} /$ ethanol solution significantly $(\mathrm{p}<0.05)$ decreased the severity of lesions by 47 and $70 \%$, respectively. These agents confer a direct topical effect on gastric mucosa, which is an undesirable sequela and a suitable model to investigate products with possible cytoprotective activity [30]. When the gastric mucosal defense is compromised by exogenous agents such as ethanol, these compounds penetrate into gastric mucosa and damage the mucosal microvessels [31]. The AD was able to reduce stress-induced ulcers diminishing the lesions in relation to the control group at all $\mathrm{AD}$ doses $(250,500$ and $1,000 \mathrm{mg} / \mathrm{Kg})$. Stress causes sympathetic stimulation of the stomach which induces direct arteriolar vasoconstriction and gradually reduces the blood flow to the stomach, leading to local hypoxia and ischemia [32]. Ischemia increases the leakage of $\mathrm{O}_{2}$ from the mitochondrial electron transport chain [33] and facilitates the availability of "redox-active" copper and iron. This leakage of $\mathrm{O}_{2}$ can cause lipid peroxidation and lead to a loss of membrane fluidity, impairment of both ion transport and membrane 
integrity, and a loss of cellular functions [34]. These two factors play a joint role in gastric ulcers induced by stress.

Figure 1. Effects of different doses of aqueous decoction (AD) of Mangifera indica leaves on models of gastric lesions induced in mice and rats $(\mathrm{mm})$.

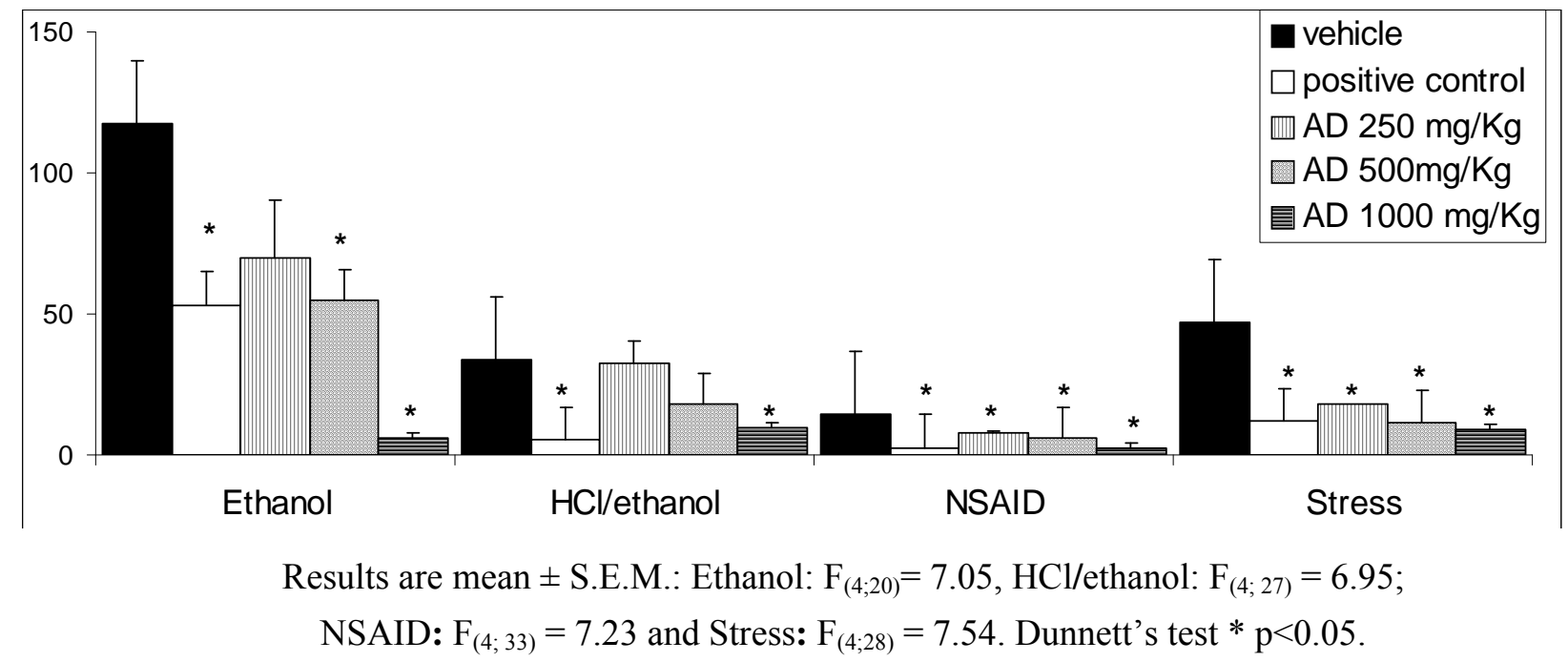

NSAIDs are the most widely used pharmacological agents in the treatment of pain, inflammation and fever. However $15-30 \%$ of patients taking NSAIDs develop peptic ulcers [35]. It is well known that prostaglandins (PGs) play a key role in protecting the gastric mucosa against injury caused by a variety of necrotizing agents [36]. Under the NSAID model, AD showed significant $(\mathrm{p}<0.05)$ activity at doses of $250(61 \%)$ and $500 \mathrm{mg} / \mathrm{Kg}(75 \%), 1,000 \mathrm{mg} / \mathrm{Kg}(82 \%)$ in relation to vehicle-treated animals. This drop in the severity of lesions by augmentation of AD doses demonstrated an important difference between aqueous decoction of $M$. indica obtained from flowers and leaves. Lima et al. [25] concluded that the absence of gastroprotective activity at the highest dose of AD obtained from flowers probably was due to the chemical compounds in this preparation which induced modulation of endogenous prostaglandins.

The aqueous decoction from Mangifera indica leaves presents a different phytochemical profile from the flowers. The phytochemical study of $\mathrm{AD}$ of leaves leads to isolation of two phenolic compounds, Mi1 and Mi2. Compound Mi1 was obtained as an amorphous yellow solid. The ${ }^{13} \mathrm{C}-\mathrm{NMR}$ spectrum of compound Mil was in complete agreement with the one reported for mangiferin (Figure 2), a $C$-glucopyranoside of 1,3,6,7-tetrahydroxyxanthone [37], occurring in a variety of plants. The compound Mi2 was identified by spectral analysis as 3-C- $\beta$-D-glucopyranosyl-4',2,4,6tetrahydroxybenzophenone (Figure 3), a $C$-glucosylbenzophenone.

Figure 2. Structure of Mi1, mangiferin, isolated from M. indica leaves.

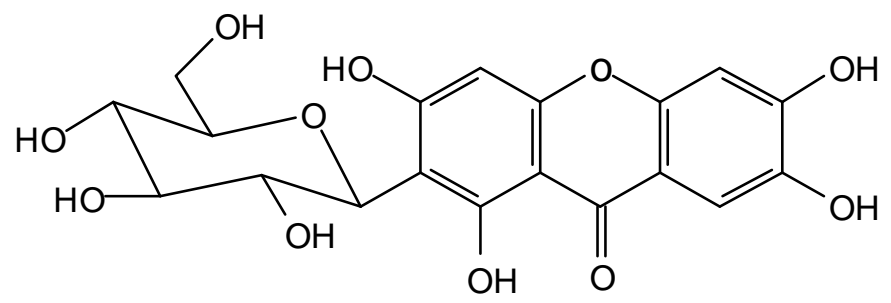


Figure 3. Structure of Mi2, benzophenone $C$-glycoside, isolated from $M$. indica leaves.<smiles>O=C(c1ccc(O)cc1)c1c(O)cc(O)c(C2OC(CO)C(O)C(O)C2O)c1O</smiles>

The HPLC-PDA chromatogram of AD showed the presence of two intense peaks at $254 \mathrm{~nm}$ with retention times of 11.6 and $40.5 \mathrm{~min}$, respectively (Figure 4). The UV spectra of these peaks, together with the analysis of retention time of standard compounds, indicated the isolated Mi2 and Mi1, respectively. The total phenolic content obtained in AD from leaves was greater than the percentage (57.3\%) present in AD of $M$. indica flowers [25].

Figure 4. HPLC-UV-PDA fingerprint of the AD of Mangifera indica leaves 1: benzophenone glycoside; 2: mangiferin. Detection at $254 \mathrm{~nm}$. Chromatographic conditions: see text.

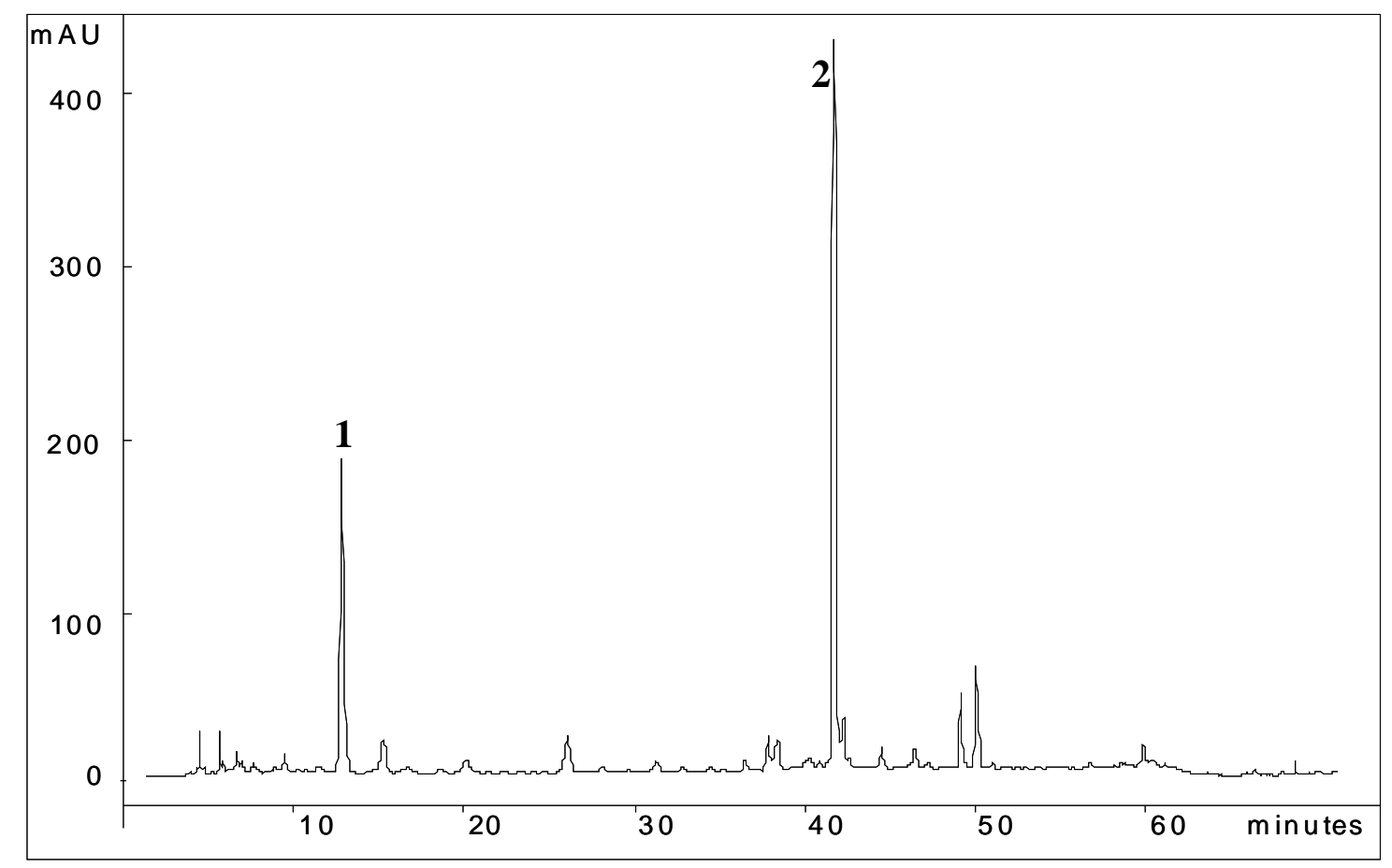

Many experiments have also demonstrated the role of antioxidants in preventing various human diseases by preventing oxidative stress and damage in biological tissues [38]. Due to the presence of conjugated ring structures and hydroxyl groups, most phenolic compounds have the potential to function as antioxidants by scavenging the superoxide anion, hydroxyl radical and peroxy radical or quenching singlet oxygen, thus inhibiting lipid peroxidation in biological systems. $M$. indica represents a rich source of phenolic compounds $[39,40]$. 
Mangiferin (2- $\beta$-D-glucopyranosyl-1,3,6,7-tetrahydroxy-9H-xanthen-9-one), is a xanthone commonly found in various parts of $M$. indica and has attracted considerable interest in view of its numerous therapeutic effects including, for example, antitumor [41], antiviral [42], antidiabetic [43], anti-inflammatory [44] and potent antioxidant [17,45,46] properties. A close association between the antioxidant activity and antiulcerogenic effect has also been also reported in many studies [38]. One recent work described the antiulcerogenic activity of mangiferin against gastric damage induced by ethanol and indomethacin [47]. This polyphenol is capable of acting as an antioxidant through many mechanisms available in vitro: primarily as potent scavenger of free radicals [48]; as modulating the activation and functionality of rat macrophages, through partial inhibition of ROS and RNS production [13] and by its ability to bind to iron-complex ions $\left(\mathrm{Fe}^{2+} \beta^{\beta+}\right)$, resulting in membrane lipid peroxidation protection [49]. The catechol moiety with a 6,7-dihydroxylated structure, together with its aromatic bonds, has been proposed as being responsible for its antioxidant property [45]. During protection afforded against free radical production, the catechols are oxidized, generating products including semiquinone radicals and quinones.

Another important class of compounds found in the AD were benzophenones, obtained from natural products or by synthetic transformations [50]. This group displays many biological activities including antioxidant, anti-inflammatory [51], antitumor [52] and antimicrobial properties [53,54]. In addition, some studies have shown the activity of benzophenones against $H$. pylori [55,56], contributing to the healing effects of $\mathrm{AD}$ from $M$. indica.

\section{Conclusions}

In the present work, the aqueous decoction from leaves of Mangifera indica did not show acute toxicity but exhibited gastroprotective effects against several ulcerogenic agents. We also demonstrated that in this decoction of $M$. indica leaves the main bioactive molecules are xanthones (mangiferin) and benzophenone glycoside.

\section{Experimental}

\section{General}

Structures of compounds were determined by combining the ${ }^{1} \mathrm{H}-,{ }^{13} \mathrm{C}$, and $2 \mathrm{D}-\mathrm{NMR}$ techniques and by comparing their spectroscopic data with those reported in the literature [37]. NMR spectra in DMSO- $d_{6}$ were obtained using a Varian INOVA 500 spectrometer, operating at $11.7 \mathrm{~T}$. Chemical shifts are given as $\delta(\mathrm{ppm})$ using TMS as internal standard. Mass spectra were registered with a Termo Finnigan LCQ Deca ion-trap and Excalibur software. The sample was prepared in $\mathrm{MeOH}$ and analyzed in negative ion mode (capillary $-4 \mathrm{~V}$, spray $5 \mathrm{kV}$, lent offset $0 \mathrm{~V}$, capillary temperature $280^{\circ} \mathrm{C}$, dry gas nitrogen at flow a rate of 50, scan 230-1800, injection time $50 \mathrm{~ms}, 3$ microscans, collision energy 25\%). The scan range was $\mathrm{m} / z$ 80-2.000. Analytical TLC was performed on Kieselgel 60 F254 (Merck) plates with $0.2 \mathrm{~mm}$ layer thickness. Spots were visualized by UV light or by spraying with anisaldheyde $/ \mathrm{H}_{2} \mathrm{SO}_{4}$ solution after heading. Column chromatography (CC) was performed by gel permeation chromatography using a Sephadex LH-20 column (Pharmacia) and silicagel 60 (Merck). Compounds were purified using a semipreparative HPLC Knauer Chance system equipped with a 
Waters R401 refractive index detector, a Phenomenex Luna column (RP 18, $10 \mu \mathrm{m}, 250 \times 10 \mathrm{~mm}$ ) and a Rheodyne injector with a $100 \mu \mathrm{L}$ sample loop). All solvents for chromatographic separation were of analytical grade, from Synthlab. The chemicals and solutions used were all of analytical grade. All drugs and reagents were prepared immediately before use. The following substances and drugs were used: absolute ethanol, hydrochloric acid, acetic acid (Sinth, Brazil), cimetidine (Sigma, U.S.A), lansoprazole and piroxicam (Hexal, Brazil).

\section{Plant material, extraction and isolation}

Leaves of $M$. indica were collected in Finca San José, Mazatenango, Suchitepéquez (Guatemala). Samples of the leaves were identified by the staff of Armando Cáceres and a voucher specimen is kept at the Herbarium of Farmaya Laboratory, Guatemala, under the number 810. For this study, Mangifera indica leaves were employed in decoction form obtained as follows: The powdered plant (300 g) was extracted with water $(500 \mathrm{~mL})$, boiled for $30 \mathrm{~min}$. The mixture was filtered with Whatman number 1 filter paper, cooled and filtered a second time. The filtrate (AD) was lyophilized with a dry-drug yield of $13.05 \%$. This extract was stored in a refrigerator at $10^{\circ} \mathrm{C}$ until used and dissolved in distilled water on the day of the experiment to prepare the stock solution and different dilutions for the purpose of pharmacological or chemical evaluation.

The AD (2.0 g) was subjected to chromatography over gel permeation $(10 \mathrm{x} 2.5 \mathrm{~cm}$ i.d.) using $\mathrm{MeOH}$ as eluent. Fractions $(5 \mathrm{~mL})$ were collected and checked by TLC on silica-gel plates, mobile phase $\mathrm{CHCl}_{3} / \mathrm{MeOH} / n-\mathrm{PrOH} / \mathrm{H}_{2} \mathrm{O}$ (5:6:1:4, v/v, organic phase). The eluents were combined according to TLC control. Fraction 9 was sequentially purified by $\mathrm{CC}$ on silica gel $(60 \mathrm{H}$, Merck) column $(10 \mathrm{x} 5$ $\mathrm{cm}$ i.d.) and eluted using solvent mixtures composed of $\mathrm{CHCl}_{3} / \mathrm{MeOH}$. The $80 \% \mathrm{MeOH}$ fraction afforded a yellow crystalline powder $(15 \mathrm{mg})$ denominated Mil. Fraction 5 was further purified using a HPLC-IR. Isocratic elution using $\mathrm{MeOH} / \mathrm{H}_{2} \mathrm{O}(45: 55, \mathrm{v} / \mathrm{v})$ as mobile phase, at flow rate of 1.5 $\mathrm{mL} / \mathrm{min}$, yielded the benzophenone glycoside $\mathrm{Mi} 2(12 \mathrm{mg})$.

\section{Quantitative determination of phenolic content in $A D$}

The global polyphenol content of AD was determined by the Folin-Ciocalteu colorimetric method proposed by Singleton and Rossi [57] with some modifications. An aliquot of the extract $(0.100 \mathrm{mg})$ was dissolved in $\mathrm{MeOH}(2 \mathrm{~mL})$, and the extracts were diluted 10-fold with water. Folin-Ciocalteu reagent $(0.25 \mathrm{~mL}, 1: 1, \mathrm{v} / \mathrm{v}$, Merck) was added to the diluted solutions $(0.25 \mathrm{~mL})$ then distilled water $(2.0 \mathrm{~mL})$ and a $200 \mathrm{~g} / \mathrm{L}$ solution of $\mathrm{Na}_{2} \mathrm{CO}_{3}(0.25 \mathrm{~mL})$ were added. After $30 \mathrm{~min}$ at room temperature, the absorbance was measured at $760 \mathrm{~nm}$ (Hach Dr-4000U spectrophotometer) with a blank sample (water plus reagents) in the reference cell. Quantification was expressed by reporting the absorbance in the calibration curve of gallic acid (Vetec $\left.{ }^{\circledR}\right)$, used as phenol standard. All samples were analyzed in triplicate. 


\section{Chemical fingerprint of $A D$}

The chromatographic profile of AD was performed using a Varian, ProStar HPLC system equipped with an RP-18 column $(250 \mathrm{~mm} \times 4.6 \mathrm{~mm}$ i.d., $5 \mu \mathrm{m}$, Phenomenex Luna). The mobile phase was water (A) and acetonitrile (B) starting with linear gradient elution of $21-30 \%$ of B in 30 min, 30-36\% of $\mathrm{B}$ in $50 \mathrm{~min}$ and $36-100 \%$ in $60 \mathrm{~min}$ eluted at a flow-rate of $1.17 \mathrm{~mL} / \mathrm{min}$, and the effluent was monitored using a ProStar 330 photodiode-array ultraviolet detection (PDA) system. Spectral data from all peaks were registered in the range $200-400 \mathrm{~nm}$. An aliquot $(5.0 \mathrm{mg})$ of AD was dissolved in ultra-pure water and filtered with a $0.22 \mu \mathrm{m}$ membrane (Millipore) to an appropriate solution of 1.0 $\mathrm{mg} / \mathrm{mL}$. The injection volume for samples was $20 \mu \mathrm{L}$ onto the HPLC column.

\section{Spectral data of compounds}

Mil: Yellow crystalline solid; $\mathrm{mp} 27{ }^{\circ} \mathrm{C}$; IR $(\mathrm{KBr}) v_{\max }$ : $3.400(\mathrm{OH}), 1.645(\mathrm{C}=\mathrm{O}) \mathrm{cm}^{-1}$; $\mathrm{UV}(\mathrm{MeOH})$ $\lambda_{\max } 240,259,316,365 \mathrm{~nm}$. EI-MS m/z: 423 [M+H] ${ }^{+}$; H-NMR (DMSO- $\left.d_{6}\right) \delta: 7.36(1 \mathrm{H}, \mathrm{s} \mathrm{H}-8), 6.84$ $(1 \mathrm{H}, \mathrm{s}, \mathrm{H}-5), 6.36(1 \mathrm{H}, \mathrm{s}, \mathrm{H} 4), 4.60\left(1 \mathrm{H}, \mathrm{d}, J=9.8 \mathrm{~Hz}\right.$, glc H-1), 3.19-4,04 (sugar prótons); ${ }^{13} \mathrm{C}-\mathrm{NMR}$ (DMSO- $\left.d_{6}\right) \delta$ : 177.1 (C-9), 162.3 (C-3), 160.2 (C-1), 154.8 (C-6, C4a), 149.5 (C-10a), 142.6 (C-7), 111.2 (C-8a), 107.7 (C-8), 107.3 (C-2), 102.4 (C-5), 101.1 (C-9a), 93.3 (C-4), 81.8 (C-5'), 79.3 (C-3'), 73.5 (C-1'), 71.1 (C-2'), 70.7 (C-4'), 62.2 (C-6').

Mi2: Brown amorphous solid; IR (KBr) $v_{\max }$ : $3.300(\mathrm{OH}), 1.615(\mathrm{C}=\mathrm{O}) \mathrm{cm}^{-1}$. UV $(\mathrm{MeOH}) \lambda_{\max } 210$, 294 nm. EI-MS m/z: 407 [M-H]', 287 [M-H-120]; ${ }^{1} \mathrm{H}-\mathrm{NMR}$ (DMSO-d $)$ ) 7.55 (2H, d, $J=8.0 \mathrm{~Hz}, \mathrm{H}-$ 2', H-6'), 6.77 (2H, d, J=8.0 Hz, H-3', H-5'), 5.95 (1H, s, H6), 4.59 (1H, d, J=10.0 Hz, glc H-1), 3.193.58 (sugar protons); ${ }^{13} \mathrm{C}-\mathrm{NMR}$ (DMSO- $d_{6}$ ) $\delta$ : 194.6 (C-7), 161.3 (C-4'), 159.1 (C-4), 157.4 (C-3), 156.8 (C-2), 131.4 (C-2', C-6'), 130.7 (C-1'), 114.6 (C-3', C-5'), 106.9 (C-1), 103.6 (C-5), 94.9 (C-6), 81.0 (C-5'), 78.3 (C-3'’), 74.6 (C-1'’), 71.9 (C-2'’), 69.6 (C-4'’), 60.5 (C-6’').

\section{Animals}

Male Swiss albino mice (25-35 g) and male Wistar albino rats (150-250 g) from the Central Animal House of the UNESP were used. The animals were fed a certified Nuvilab ${ }^{\circledR}$ (Nuvital) diet with free access to tap water under standard conditions of $12 \mathrm{~h}$ dark-12 $\mathrm{h}$ light, humidity $(60 \pm 1.0 \%)$ and temperature $(21 \pm 1 \%)$. Fasting was used prior to all assays because standard drugs and infusion were always administered orally (by gavage) or intraduodenally using a saline solution $(10 \mathrm{~mL} / \mathrm{Kg})$ as the vehicle. Moreover, the animals were kept in cages with raised floors of wide mesh to prevent coprophagy. The number of animal was enough the statistical analysis and we reduced number of animals to respect the Ethical Animal Care. The animals were killed by $\mathrm{CO}_{2}$ gas ( 1 min with outflow $15 \mathrm{~L} / \mathrm{min}$ ) and all experiments following the recommendations of the Canadian Council on Animal Care [58] and all of the employed protocols were approved by UNESP Institutional Animal Care and Use Committee. 


\section{Acute toxicity}

The acute toxicity studies of $M$. indica were performed in mice. In this assay, increasing doses of $\mathrm{AD}$ were orally administered to groups of ten animals for each dose after a $12 \mathrm{~h}$ fast. Animals receiving the vehicle (saline) served as control. The signs and symptoms associated with the AD administration $(5 \mathrm{~g} / \mathrm{Kg}$, p.o.) were observed at 0, 30, 60, 120, 180 and $240 \mathrm{~min}$ after and then once a day for the next 14 days. At the end of the period the number of survivors was recorded. The acute toxicological effect was estimated by the method described by Souza Brito [59].

Gastroprotective effect against different ulcerogenic agents: $\mathrm{HCl} /$ ethanol-induced ulcer [60] - Mice were divided into groups $(\mathrm{n}=6-7)$ that had each fasted for $24 \mathrm{~h}$ prior to oral dosing with the vehicle (10 $\mathrm{mL} / \mathrm{Kg})$, lansoprazole $(30 \mathrm{mg} / \mathrm{Kg})$ and $\mathrm{AD}(250,500$ or $1,000 \mathrm{mg} / \mathrm{Kg})$. Fifty minutes after the treatments, all animals received a $0.3 \mathrm{M} \mathrm{HCl} / 60 \% \mathrm{EtOH}$ solution $(0.2 \mathrm{~mL})$ orally. Animals were killed $1 \mathrm{~h}$ after the administration of $\mathrm{HCl} / \mathrm{EtOH}$ solution. The stomachs were removed, opened along the greater curvature and fixed between two glass plates. Ulcerative lesions were calculated according to the methodology described by Szelenyi and Thiemer [61]. Indomethacin-induced gastric ulcers in mice according to Rainsford [62] - In this model, gastric lesions were induced with indomethacin (30 $\mathrm{mg} / \mathrm{Kg}$, s.c.) and administered to mice ( $\mathrm{n}=7-8)$ after a $24 \mathrm{~h}$ fast. The $\mathrm{AD}(250,500$ or 1,000 mg/Kg), cimetidine $(100 \mathrm{mg} / \mathrm{Kg})$ or vehicle was administered orally $30 \mathrm{~min}$ before the induction of gastric ulcer. The animals were killed $4 \mathrm{~h}$ after treatment with the ulcerogenic agent. The stomachs were removed and ulcerative lesions were calculated as described previously. Absolute-Ethanol-induced damage [30] - After a total of $24 \mathrm{~h}$ fasting, five groups of rats $(\mathrm{n}=5)$ received an oral administration of $\mathrm{AD}(250,500$ or $1,000 \mathrm{mg} / \mathrm{Kg})$, lansoprazole $(30 \mathrm{mg} / \mathrm{Kg})$ or vehicle $(10 \mathrm{~mL} / \mathrm{Kg})$. One hour after treatment, all rats received one $\mathrm{mL}$ of $99.5 \%$ ethanol to induce gastric ulcer. The animals were killed one hour after treatment with the ulcerogenic agent and the stomachs removed to determine the lesion damage. Hypothermic Restraint Stress Ulcer [63]. After having fasted for $24 \mathrm{~h}$, mice $(\mathrm{n}=7-8)$ received an oral administration of $\mathrm{AD}(250,500$ or $1,000 \mathrm{mg} / \mathrm{Kg})$, cimetidine $(100 \mathrm{mg} / \mathrm{Kg})$ or vehicle $(10$ $\mathrm{mL} / \mathrm{Kg}$ ). One hour after treatment, mice were immobilized in a restraint cage at $4{ }^{\circ} \mathrm{C}$ for $4 \mathrm{~h}$ to induce gastric ulcer. The animals were killed and the stomachs removed and opened along the greater curvature to determine the number of gastric lesions. The differences between the times of oral administration of $\mathrm{AD}$ are in accordance to animal species and metabolisms and all methods are in accordance to authors that standardized each one.

\section{Statistical analysis}

Results are expressed as mean \pm S.E.M. Statistical significance was determined by one-way analysis of variance followed by Dunnett's or Student's test, with the level of significance at $p<0.05$.

\section{Acknowledgements}

This study was supported by grants from Fundação de Amparo à Pesquisa do Estado de São Paulo (FAPESP) and Conselho Nacional de Desenvolvimento Científico e Tecnológico (CNPq). 


\section{References and Notes}

1. Qvistad, G.; Waldum, H. Rebound hypersecretion after inhibition of gastric acid secretion. Basic Clin. Pharmacol. Toxicol. 2004, 94, 202-208.

2. Hirschowitz, B.I.; Keeling, D.; Lewin, M.; Okabe, S.; Parsons, M.; Sewing, K.; Wallmark, B.; Sachs, G. Pharmacological aspects of acid secretion. Dig. Dis. Sci. 1995, 40, 3-23.

3. Ross, I.A. Medicinal plants of the world; Human Press Inc.: New Jersey, USA, 1999; pp.199-202.

4. Robineau, L.G.; Soejarto, D.D. In Medicinal Resources of the Tropical Forest; Balick, M.J., Elisabetsky, E., Laird, S.A., Eds.; Columbia University Press: New York, USA, 1996; pp. 318325.

5. Robineou, L.G. Hacia una Farmacopea Caribeña; Enda-Caribe: Santo Domingo, República Dominicana, 1995; pp. 351-353.

6. Singh, U.P.; Singh, D.P.; Singh, M.; Maurya, S.; Srivastava, J.S.; Singh, R.B.; Singh, S.P. Characterization of phenolic compounds in some Indian mango cultivars. Int. J. Food Sci. Nutr. 2004, 55, 163-169.

7. Selles, N.A.J.; Castro, H.T.V.; Aguero-Aguero, J.; Gonzalez, J.; Nadeo, F.; De Simone, F.; Rastelli, L. Isolation and quantitative analysis of phenolic antioxidants, free sugars, and polyols from mango (Mangifera indica L) stem bark aqueous decoction used in Cuba as a nutritional supplement. J. Agric. Food Chem. 2002, 50, 762-766.

8. Anjaneyulu, V.; Babu, I.S.; Connollu, J.D. 29-hydroxymangiferonic acid from Mangifera indica. Phytochemistry 1994, 35, 1301-1303.

9. Kharn, M.A.; Nizami, S.S.; Khan, M.N.I.; Azeem, S.W.; Ahamed, Z. New triterpenes from Mangifera indica. J. Nat. Prod. 1994, 57, 988-991.

10. Saleh N.A; El-Ansari M.A. Polyphenolics of twenty local varieties of Mangifera indica. Planta Med. 1975, 28, 124-130.

11. Garrido, G.; Gonzalez, D.; Delporte, C.; Backhouse, N.; Quintero, G.; Nunez-Selles, A.J.; Morales, M.A. Analgesic and anti-inflammatory effects of Mangifera indica L. extract (Vimang). Phytother. Res. 2001, 15, 18-21.

12. Makare, N.; Bodhankar, S.; Rangari, V. Immunomodulatory activity of alcoholic extract of Mangifera indica L. in mice. J. Ethnopharmacol. 2001, 78, 133-137.

13. Garcia, D.; Delgado, R.; Ubeira, F.M.; Leiro, J. Modulation of rat macrophage function by the Mangifera indica L. extracts Vimang and mangiferin. Int. Immunopharmacol. 2002, 2, 797-806.

14. Garcia, D.; Leiro, J.; Delgado, R.; Sanmartin, M.L.; Ubeira, F.M. Mangifera indica L. extract (Vimang) and mangiferin modulate mouse humoral immune responses. Phytother. Res. 2003a, 17, 1182-1187.

15. Martinez, G.; Delgado, R.; Perez, G.; Garrido, G.; Nunez Selles, A.J.; Leon. O.S. Evaluation of the in vitro antioxidant activity of Mangifera indica L. extract (Vimang). Phytother. Res. 2000, 14, 424-427.

16. Sanchez, G.M.; Rodríguez, H.M.A.; Giuliani, A.; Núñez Sellés, A.J.; Rodríguez, N.P.; León Fernández, O.S.; Re, L. Protective effect of Mangifera indica L. extract (Vimang) on the injury associated with hepatic ischaemia reperfusion. Phytother. Res. 2003, 17, 197-201.

17. Sanchez, G.M.; Re, L.; Giuliani, A.; Nunez-Selles, A.J.; Davison, G.P.; Leon-Fernandez, O.S. Protective effects of Mangifera indica L. extract, mangiferin and selected antioxidants against 
TPA-induced biomolecules oxidation and peritoneal macrophage activation in mice. Pharmacol. Res. 2000, 42, 565-573.

18. Sairam, K.; Hemalatha, S.; Kumar, A.; Srinivasan, T.; Ganesh, J.; Shankar, M.; Venkataraman, S. Evaluation of anti-diarrhoeal activity in seed extracts of Mangifera indica. J. Ethnopharmacol. 2003, 84, 11-15.

19. Anila, L.; Vijayalakshmi, N.R. Flavonoids from Emblica officinalis and Mangifera indicaeffectiveness for dyslipidemia. J. Ethnopharmacol. 2002, 79, 81-87.

20. Aderibigbe, A.O.; Emudianughe, T.S.; Lawal, B.A. Antihyperglycaemic effect of Mangifera indica in rat. Phytother. Res. 1999, 13, 504-507.

21. Aderibigbe, A.O.; Emudianughe, T.S.; Lawal, B.A. Evaluation of the antidiabetic action of Mangifera indica in mice. Phytother. Res. 2001, 15, 456-458.

22. Tona, L.; Kambu, K.; Ngimbi, N.; Mesia, K.; Penge, O.; Lusakibanza, M.; Cimanga, K.; De Bruyne, T.; Apers, S.; Totte, J.; Pieters, L.; Vlietinck, A.J. Antiamoebic and spasmolytic activities of extracts from some antidiarrhoeal traditional preparations used in Kinshasa, Congo. Phytomedicine 2000, 7, 31-38.

23. Garcia, D.; Escalante, M.; Delgado, R.; Ubeira, F.M.; Leiro, J. Anthelminthic and antiallergic activities of Mangifera indica L. stem bark components Vimang and mangiferin. Phytother. Res. 2003b, 17, 1203-1208.

24. Bairy, I.; Reeja, S.; Siddharth, R.P.S.; Bhat, M.; Shivananda. P.G. Evaluation of antibacterial activity of Mangifera indica on anaerobic dental microflora based on in vivo studies. Indian J. Pathol. Microbiol. 2002, 45, 307-310.

25. Lima, Z.P.; Severi, J.A.; Pellizzon C.H.; Brito, A.R.M.S.; Solis, P.N.; Cáceres, A.; Girón, L.M.; Vilegas, W.; Hiruma-Lima, C.A. Can the aqueous decoction of mango flowers be used as an antiulcer agent? J. Ethnopharmacol. 2006, 106, 29-37,

26. Loomis, T.A.; Hayes, A.W. Essentials of Toxicology (4 edn); Academic Press Limited: London, 1996; pp. 33-46.

27. Szabo, S.; Trier, J.S.; Frankel, P.W. Sulfhydryl compounds may mediate gastric cytoprotection. Science 1981, 214, 200-202.

28. La Casa, C.; Villegas, I.; Alarcon de la Lastra, C.; Motilva, V.; Martin Balero, M.J. Evidence for protective and antioxidant properties of rutin, natural flavone, against ethanol induced gastric lesions. J. Ethnopharmacol. 2000, 71, 45-53.

29. Stadman, E.R.; Berlett, B.S. In: Free Radical Toxicology; Wallace, K.B., Ed.; Taylor \& Francis, Bristol, USA, 1997; pp. 71-87.

30. Morimoto, Y.; Shimohara, K.; Oshima, S.; Sukamoto, T. Effects of the new anti-ulcer agent KB5492 on experimental gastric mucosal lesions and gastric mucosal defensive factors, as compared to those of teprenone and cimetidine. Jpn. J. Pharmacol. 1991, 57, 495-505.

31. Atay, S.; Tarnawski, A.S.; Dubois, A. Eicosanoids and the stomach. Prostaglandin their lipid mediat. 2000, 61, 105-124.

32. Takeuchi, K.; Furukawa, O.; Okada, M.; Niida, H.; Okabe, S. Influence of stress on gastric alkaline secretion in rats. J. Pharmacol. Exp.Ther. 1990, 252, 1228-1233.

33. Blake, D.R.; Allen, R.E.; Lunee, J. Free radicals in biological systems- a review oriented to inflammatory process. Br. Med. Bull. 1987, 43, 371-385. 
34. Halliwell, B.; Gutteridge, J.M.C. Role of free radicals and catalytic metal ions in human disease. Methods Enzymol. 1990, 186, 1-85.

35. Nishida, T.; Tsujii, M.; Tsujii, S. Are COX-2 inhibitors truly able to prevent NSAIDs- associated ulcers? Nippon Rinssho 2004, 62, 561-565.

36. Gudis, K.; Sakamoto, C. The role of cycloxygenase in gastric mucosal protection. Dig. Dis.Sci. 2005, 50, s16-s23.

37. Shahat, A.A.; Hassan, R.A.; Nazif, N.M.; Miert, S.V.; Pieters, L.; Hammuda, F.M.; Vlietinck, A.J. Isolation of Mangiferin from Bombax malabaricum and structure revision of shaminin. Planta Med. 2003, 69, 1068-1070.

38. Repetto, M.G.; Lesuy, S.F. Antioxidant properties of natural compounds used in popular medicine for gastric ulcers. Braz. J. Med. Biol. Res. 2002, 35, 523-534.

39. Schieber, A.; Ullrich, W.; Carle, R. Characterization of polyphenols in mango puree concentrate by HPLC with diode array and mass spectrometric detection. Innov. Food Sci. Emerg. 2000, 1, 161-166.

40. Schieber, A.; Berardini, N.; Carle, R. Identification of flavonol and xanthone glycosides from mango (Mangifera indica L. Cv. "Tomy Atkins") peels by High-Performance Liquid Chromatography-Electrospray Ionizations Mass Spectrometry. J. Agric. Food Chem. 2003, 51, 5006-5011.

41. Yoshimi, N.; Matsunaga, K.; Katayama, M.; Yamada, Y.; Kuno, T.; Qiao, Z.; Hara, A.; Yamahara, J.; Mori, H. The inhibitory effects of mangiferin, a naturally occurring glucosylxanthone, in bowel carcinogenesis of male F344 rats. Cancer Lett. 2001, 163, 163-170.

42. Zheng, M. S.; Lu, Z. Y. Antiviral effects of mangiferin and isomangiferin on Herpes simples virus. Chin. Med. J. 1990, 103, 160-165.

43. Miura, T.; Ichiki, H.; Hashimoto, I.; Iwamoto, N.; Kato, M.; Kubo. M.; Ishihara. E.; Komatsu, Y.; Okada. M.; Ishida, T.; Tanigawa, K. Antidiabetic activity of a xanthone compound, mangiferin. Phytomedicine 2001, 8, 85-87.

44. Garrido, G.; González, D.; Lemus, Y.; García, D.; Lodeiro, L.; Quintero, G.; Delporte, C.; NúñezSellés, A.J.; Delgado, R. In vivo and in vitro anti-inflammatory activity of Mangifera indica L. extract (Vimang). Pharmacol. Res. 2004, 50, 143-149.

45. Sato, T.; Kawamoto, A.; Tamura, A.; Tatsumi, Y.; Fujii, T. Mechanism of antioxidant action of pueraria glycoside (PG)-1 (an isoflavonoid) and mangiferin (a xanthonoid). Chem. Pharm. Bull. 1992, 721-724.

46. Markus, B. Electrochemical behavior and antioxidant activity of some natural polyphenols. Helv. Chim. Acta 1996, 79, 1147-1158.

47. Carvalho, A.C.S.; Guedes, M.M.; Souza, A.L.; Trevisan, M.T.S.; Lima, A.F.; Santos, F.A.; Rao, V.S.N. Gastroprotective effect of mangiferin, a xanthonoid from Mangifera indica, against gastric injury induced by ethanol and indomethacin in rodents. Planta Med. 2005, 73, 1372-1376.

48. Leiro, J. M.; Álvarez, E.; Arranz, J. A.; Siso, I. G.; Orallo, F. In vitro effects of mangiferin on superoxide concentrations and expression of the inducible nitric oxide synthase, tumor necrosis factor- $\alpha$ and transforming growth factor- $\beta$ genes. Biochem. Pharmacol. 2003, 65, 1361-1371. 
49. Andreu, G.P.; Delgado, R.; Velho, J.A.; Curti, C.; Vercesi, A. E. Iron complexing activity of mangiferin, a naturally occurring glucosylxanthone, inhibits mitochondrial lipid peroxidation induced by $\mathrm{Fe}^{2+}$-citrate Eur. J. Pharmacol. 2005, 513, 47-55.

50. Baggett, S.; Mazzola, E.P.; Kennelly, E.J. The benzophenones: Isolation, structural elucidation and biological activities. Stud. Nat. Prod. Chem. 2005, 32, 721-771.

51. Venu, T.D.; Shashikanth, S.; Khanum, S.A.; Naveen, S.; Firdouse, A.; Sridhar, M.A.; Prasad, J.S. Synthesis and crystallographic analysis of benzophenone derivatives-The potential antiinflammatory agents. Bioorg. Med. Chem. 2007, 15, 3500-3514.

52. Prabhakar, B.T.; Khanum, S.A.; Jayashree, K.; Salimath, B.P.; Shashikanth, S. Anti-tumor and proapoptotic effect of novel synthetic benzophenone analogues in Ehrlich ascites tumor cells. Bioorg. Med. Chem. 2006, 14, 435-446.

53. Bakana, P.; Claeys, M.; Totte, J.; Pieters, L.A.; Van Hoof, L.; Tamba-Vemba, V.B.D.A.; Vlietinck, A.J. Structure and chemotherapeutical activity of a polyisoprenylated benzophenone from the stem bark of Garcinia huillensis. J. Ethnopharmacol. 1987, 21, 75-84.

54. Dos Santos, M. H. Estudo químico dos frutos de Rheedia gardneriana e efeito biológico de seus constituintes. Thesis, Universidade Federal de Viçosa, Minas Gerais, Brazil, 1996.

55. Chatterjee, A.; Yasmin, T.; Bagchi, D.; Stohs, S.J. The bactericidal effects of Lactobacillus acidophilus, garcinol and protykin compared to clarithromycin, on Helicobacter pylori. Mol. Cell. Biochem. 2003, 243, 29-35.

56. Ma, Y.M.; Li, Y.; Liu, J.Y.; Song, Y.C.; Tan, R.X. Anti-Helicobacter pylori metabolites from Rhizoctonia sp. Cy064, an endophytic fungus in Cynodon dactylon. Fitoterapia 2004, 75, 451456.

57. Singleton, V.L.; Rossi, J.A.Jr. Colorimetry of total phenolics with phosphomolybdicphosphotungstic acid reagents. Am. J. Enol. Vit. 1965, 16, 144-158.

58. Olfert, E.D.; Cross, B.M.; McWilliam, A.A. Guide to the Care and Use of Experimental Animals; Canadian Council on Animal Care Co.: Ontario, Canada, 1993; pp. 1-213.

49. Souza Brito, A.R.M. Manual de Ensaios Toxicológicos in vivo; Editora da Unicamp: Campinas, São Paulo, Brazil, 1995; pp.15-22.

60. Mizui, T.; Doteuchi, M. Effect of polyamines on acidified ethanol-induced gastric lesions in rats. Jpn. J. Pharmacol. 1983, 33, 939-945.

61. Szelenyi, I.; Thiemer, K. Distention ulcer as a model for testing of drugs for ulcerogenic side effects. Arch. Toxicol. 1978, 41, 99-105.

62. Rainsford, K.D. Gastric ulcerogenicity of non-steroidal anti-inflammatory drug as in mice with mucosa sensitized by cholinomimetic treatment. Biochem. Pharmacol. 1978, 27, 1281-1289.

63. Levine, R.J. In Peptic Ulcer; Pfeiffer, C.J., Ed.; Munksgaard: Copenhagen, Denmark, 1971; pp. 92-97.

Sample Availability: Samples of the compounds are available from the author.

(C) 2009 by the authors; licensee Molecular Diversity Preservation International, Basel, Switzerland. This article is an open-access article distributed under the terms and conditions of the Creative Commons Attribution license (http://creativecommons.org/licenses/by/3.0/). 